\title{
Facilitating the Dissemination of iCBT for the Treatment of Anxiety and Depression: A Feasibility Study
}

\author{
Daniella DaPonte ${ }^{1}$, France Talbot ${ }^{1 \star}$, Nickolai Titov², Blake F. Dear ${ }^{2}$, Heather D. Hadjistavropoulos ${ }^{3}$, \\ Thomas Hadjistavropoulos ${ }^{3}$ and Jalila Jbilou ${ }^{1}$ \\ ${ }^{1}$ Université de Moncton, Moncton, New Brunswick, Canada, ${ }^{2}$ Macquarie University, Sydney, New South Wales, Australia \\ and ${ }^{3}$ University of Regina, Regina, Saskatchewan, Canada \\ ${ }^{\star}$ Corresponding author. France Talbot, Ph.D., Université de Moncton, Moncton, N.-B., Canada, E1A 3 E9. \\ Email: france.talbot@umoncton.ca
}

\begin{abstract}
Translating existing internet-based cognitive-behavioural therapy (iCBT), along with the use of transdiagnostic and self-guided formats, may prove to be a cost-effective option of disseminating iCBT. Only recently have encouraging findings been reported for a self-guided delivery. This study assessed the feasibility of a French and self-guided version of an existing English iCBT course, called the Wellbeing Course, for the treatment of anxiety and depression. Existing ICBT programs have not yet been delivered in French, although this language is spoken worldwide. Thirty-one participants were included in a single group pre-post open trial with a 3-month follow-up. Feasibility outcomes were attrition, treatment adherence, acceptability, and preliminary efficacy. Primary outcome measures were the Patient Health Questionnaire 9-item (PHQ-9) and the Generalised Anxiety Disorder 7-item (GAD-7). Nearly 75\% of the participants completed the program. Over $80 \%$ of the participants provided posttreatment and follow-up data. All study completers reported that they would recommend the Wellbeing Course to a friend having similar problems. Significant reductions in symptoms of anxiety and depression were found following treatment, consistent with earlier studies. These preliminary findings support the use of the assessed strategies to facilitate the cross-cultural dissemination of iCBT for a more universal access to quality psychological care.
\end{abstract}

Keywords: anxiety; depression; internet-delivered cognitive behavioural therapy (iCBT); French; transdiagnostic; dissemination; cross-cultural

Over the past two decades, a large body of evidence has accumulated supporting the use of clinicianguided, internet-based CBT (iCBT) programs as part of a stepped care model of care for the treatment of anxiety and depression (Andrews, Cuijpers, Craske, McEvoy, \& Titov, 2010; Dear et al., 2015; Hedman et al., 2014; Hedman, Ljótsson, Kaldo et al., 2013; Hedman, Ljótsson, Rück et al., 2013; Mewton, Smith, Rossouw, \& Andrews, 2014; Mewton, Wong, \& Andrews, 2012; Olthuis, Watt, Bailey, Hayden, \& Stewart, 2016; Priemer \& Talbot, 2013; Williams \& Andrew, 2013). In a number of countries, however, access to iCBT is limited, and a majority of evidence-based programs for the treatment of anxiety and depression are in English. The International Society for Research on Internet Interventions (ISRII) has highlighted the importance of facilitating the dissemination of iCBT programs by providing translation into multiple languages (Ritterband, Andersson, Christensen, Carlbring, \& Cuijpers, 2006). Translating and implementing existing iCBT programs, rather than developing new ones, can be a highly cost-efficient strategy (Lintvedt, Griffith, Eisemann, \& Waterloo, 2013).

An established English iCBT program for the treatment of anxiety and depression is the the Wellbeing Course (Dear et al., 2011; Titov et al., 2013; Titov et al., 2014; Titov et al., 2011). This program has been successfully implemented in a clinician-guided format at a national level in Australia through the MindSpot Clinic (www.mindspot.org.au; Titov, Dear, Staples, Bennett-Levy et al., 2015; Titov et al., 2016), and in Saskatchewan, Canada, in non-specialised community clinics that were 
offering primarily face-to-face therapy services (Hadjistavropoulos et al., 2016). Its short- and longterm efficacy as well as acceptability have been supported in feasibility and randomised controlled trials. As a transdiagnostic (or unified) program, the Wellbeing Course allows the treatment of both anxiety and depressive disorders, with gains similar to disorder-specific treatments (Dear et al., 2015; Fogliati et al., 2016; Hadjistavropoulos et al., 2016; Titov, Dear, Staples, Terides et al., 2015). Compared to disorder-specific treatments, transdiagnostic treatments can have several practical benefits for both clients and service providers, including the opportunity for clients to learn to manage comorbid disorders, as well as reduced cost and training requirements, thereby increasing access to treatment.

Preliminary evidence supports the clinician-guided Wellbeing Course's transportability across cultures. Positive results have been found among cultures as diverse as the Arabic and Chinese linguistic minorities in Australia, using translated and culturally modified versions (Choi et al., 2011; Kayrouz et al., 2015). Other features of the Wellbeing Course may also be assets in the cross-cultural dissemination of iCBT, namely its transdiagnostic nature and the option to use a self-guided format of delivery without compromising treatment satisfaction or efficacy. Both features can potentially allow larger numbers of people to receive clinically and cost-effective treatments, thereby facilitating dissemination. The use of self-guided formats may also provide a better fit with clients' preference, as found in a large internet psychotherapy clinic where only 75 of 2,660 (i.e., 2\%) consecutive participants opted for clinician-guided over self-guided internet therapy (Klein, Meyer, Austin, \& Kyrios, 2011).

Previous meta-analyses revealed limited benefits for self-guided iCBT programs compared to clinician-guided ones (e.g., Andrews et al., 2010). Since then, a few self-guided iCBT programs have received preliminary support, producing similar clinical outcomes, treatment completion and satisfaction rates as guided iCBT programs for social anxiety disorder, panic disorder, generalised anxiety disorder and major depressive disorder (e.g., Dear et al., 2016; Dear et al., 2015; Fogliati et al., 2016; Titov, Dear, Staples, Terides et al., 2015). At least two key differences are likely to exist between older and newer self-guided iCBT programs (Dear et al., 2016). One is the use of a telephone contact to assess treatment suitability, to orient and prepare participants for the treatment, and to answer questions. A second difference is that newer programs have been designed to work in a self-guided format, including, for example, carefully designed automated emails to guide and reinforce people for their progression through the therapy. Such strategies are part of the self-guided delivery of the Wellbeing Course, and encouraging results have been found in a randomised controlled trial (Titov et al., 2013), with treatment gains maintained over a 12-month follow-up (Titov et al., 2014).

This feasibility study aims to assess the cross-cultural dissemination of iCBT for the treatment of anxiety and depression using a translated and self-guided version of a transdiagnostic iCBT program, the Wellbeing Course. The program was translated into French and its dissemination tested in Canada. No existing evidence-based iCBT programs are available in French, although it is spoken on all five continents with an estimated 274 million French speakers worldwide (International Organisation of La Francophonie, 2018). The conduct of such a demonstration project is of utmost importance given that access to iCBT is very limited in a number of countries, including Canada, and that additional empirical support is needed on the use of self-guided formats. Feasibility outcomes evaluated in this study were treatment adherence, attrition, treatment acceptability, and preliminary efficacy pertaining to anxiety, depression and life satisfaction. It was hypothesised that a majority of participants would: (1) complete the five lessons of the Wellbeing Course within 8 weeks, (2) report being satisfied with the Wellbeing Course, and (3) show a reduction of depression and anxiety, including generalised anxiety, social phobia, panic and agoraphobia.

\section{Method}

\section{Ethics}

The authors assert that all procedures contributing to this work comply with the ethical standards of the relevant national and institutional committees on human experimentation and with the Helsinki 
Declaration of 1975, as revised in 2008. The study was approved by the Human Research Ethics Committee of the Université de Moncton (New Brunswick, Canada), file number 1415-074. All participants provided informed consent electronically.

\section{Participants}

Participants were recruited among the general population of New Brunswick using advertisements in various media. Interested people applied online through a secure website (www.etherapies.ca). Eligibility criteria were: (1) residing in New Brunswick; (2) at least 18 years of age; (3) French as first official language spoken; (4) good understanding of written French; (5) reliable access to the internet; (6) clinical levels of depression, generalised anxiety, social anxiety or panic as indicated by the total score on at least one of the following measures: Patient Health Questionnaire-9 item (PHQ-9) > 9, Generalised Anxiety Disorder Scale-7 item (GAD-7) > 7, Liebowitz Social Anxiety Scale $>70$, and Panic and Agoraphobia Scale $\geq 19$; (7) not currently engaged in another cognitive behavioural therapy (CBT); (8) no change in medication for anxiety and depression in the past 4 weeks and no change expected over the next 2 months; and (9) willing to share personal contact information. Applicants with severe depression (score of $\geq 20$ or a score of $>2$ on item 9 [suicidal ideation] of the PHQ-9) or currently experiencing mental health problems with psychotic symptoms were not eligible to participate. Fifty individuals filled out the online screening questionnaires. Of these 50 applicants, 31 met inclusion criteria and began Lesson 1. Participant flow is shown in Figure 1. Table 1 presents sociodemographic and mental health-related characteristics of the participants.

\section{Feasibility Outcome Measures}

\section{Treatment adherence}

The percentage of participants who completed all five lessons of the Wellbeing Course within 8 weeks was used to measure adherence. Lesson completion was defined as viewing all pages of each lesson and was monitored using participants' activity logs.

\section{Attrition}

Attrition was assessed using the percentage of participants who did not complete the post-test or follow-up outcome measures.

\section{Treatment acceptability}

Treatment acceptability was assessed posttreatment using four multiple choice or yes/no questions (adapted from Titov et al., 2013): (1) 'Overall, how satisfied are you with the Course?' (totally unsatisfied, generally unsatisfied, mostly unsatisfied, neither satisfied nor unsatisfied, mostly satisfied, generally satisfied, and totally satisfied), (2) 'How would you evaluate the quality of the material?'( poor, acceptable, good, very good, excellent), (3) 'Would you recommend this treatment to a friend suffering from anxiety or depression?' ( yes or no), and (4) 'Was it worth your time doing the Course?'( yes or no). Four open-ended questions were also included to get participants' feedback on the intervention, what was the most and the least helpful to them, and any suggestions that they might have to improve the program. As well, participants provided feedback about the program over the phone at posttreatment, at which time their answers to the previous questions were reviewed.

\section{Preliminary Treatment Efficacy}

Outcome measures were self-report questionnaires administered online. Pretreatment Cronbach's alphas are reported for each measure. The primary psychological outcome measures for anxiety and depression were the same as the ones used by Titov and colleagues (2013) to facilitate comparison of the findings. Secondary measures were used to assess the impact of the program on disorder-specific 


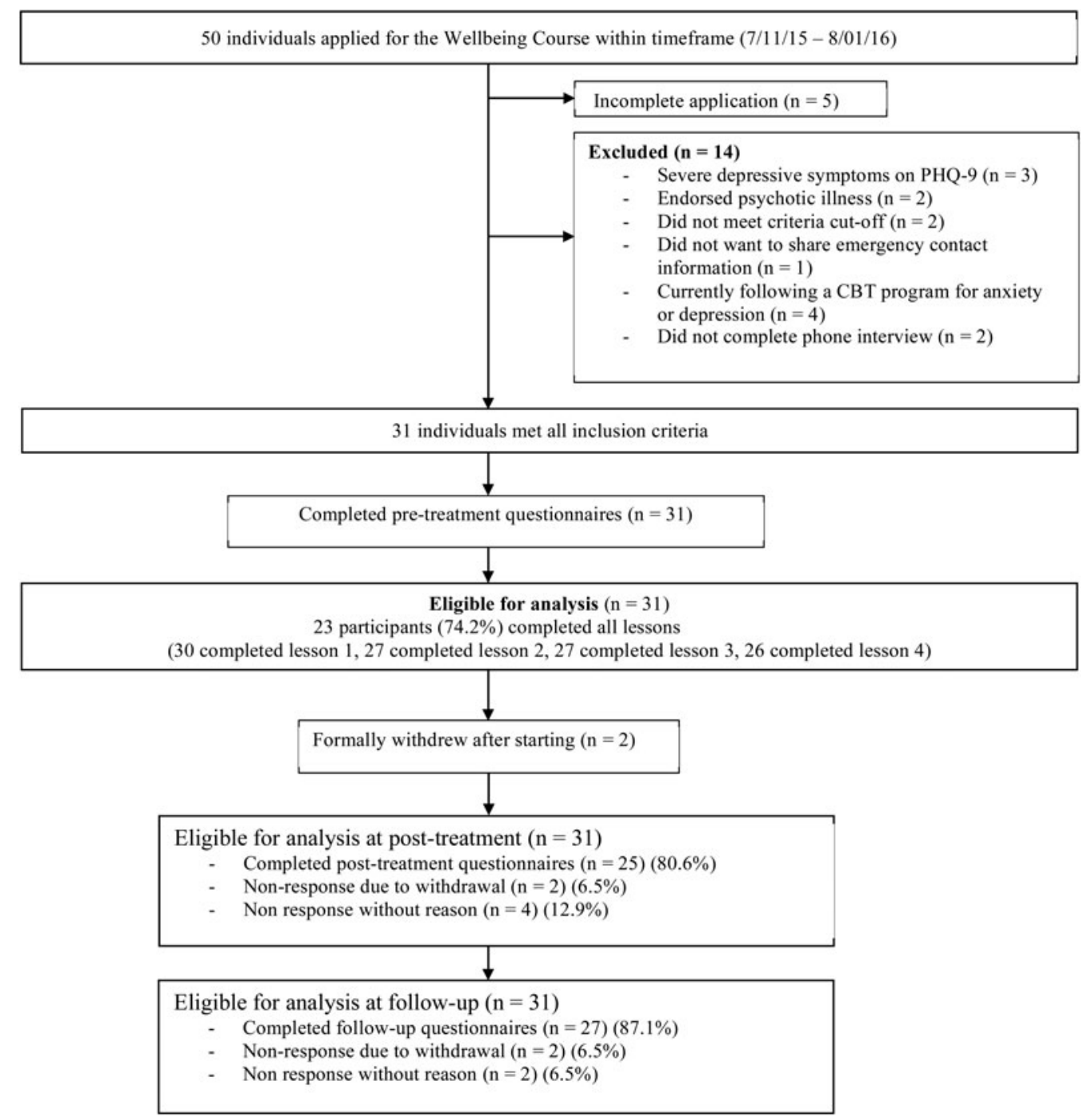

Figure 1. Study participant flow chart.

measures of anxiety, including social phobia, panic disorder with or without agoraphobia, and generalised anxiety disorder, as well as life satisfaction.

\section{Primary Psychological Outcome Measures}

Patient Health Questionnaire

(PHQ-9; Kroenke, Spitzer, \& Williams, 2001, translation by MAPI Research Institute, 2016). The PHQ-9 is a nine-item scale assessing the symptoms and severity of depression based on the DSM-IV diagnostic criteria of major depression. Item scores are summed with higher scores representing higher levels of depression $(\alpha=.77)$.

\section{Generalised Anxiety Disorder-7}

(GAD-7; Spitzer, Kroenke, Williams, \& Löwe, 2006; translation by MAPI Research Institute, 2016). The GAD-7 is a seven-item scale that measures the symptoms and severity of anxiety based on the 
Table 1. Participant Demographic Characteristics and Mental Health-Related Variables

\begin{tabular}{|c|c|c|}
\hline Variable & $n$ & $\%$ \\
\hline \multicolumn{3}{|l|}{ Sex } \\
\hline Male & 7 & 22.6 \\
\hline Female & 24 & 77.4 \\
\hline \multicolumn{3}{|l|}{ Age } \\
\hline Mean (years) & 42.6 & \\
\hline Range (years) & $22-75$ & \\
\hline \multicolumn{3}{|l|}{ Marital status } \\
\hline Married & 19 & 61.3 \\
\hline Common law & 8 & 25.8 \\
\hline Single & 4 & 12.9 \\
\hline \multicolumn{3}{|l|}{ Education } \\
\hline Secondary & 1 & 3.2 \\
\hline College & 14 & 45.2 \\
\hline University & 16 & 51.6 \\
\hline \multicolumn{3}{|l|}{ Occupation } \\
\hline Full time & 21 & 67.7 \\
\hline Part time & 4 & 12.9 \\
\hline Stay at home & 2 & 6.5 \\
\hline Retired & 3 & 9.7 \\
\hline Unemployed & 1 & 3.2 \\
\hline \multicolumn{3}{|l|}{ Annual income } \\
\hline Less than $\$ 25,000$ & 3 & 9.7 \\
\hline$\$ 25,000$ to $\$ 49,999$ & 6 & 19.4 \\
\hline$\$ 50,000$ to $\$ 74,999$ & 6 & 19.4 \\
\hline$\$ 75,000$ to $\$ 99,999$ & 7 & 22.6 \\
\hline$\$ 100,000$ to $\$ 124,999$ & 3 & 9.7 \\
\hline$\$ 125,000$ to $\$ 149,999$ & 4 & 12.9 \\
\hline$\$ 150,000$ or more & 2 & 6.5 \\
\hline Previously diagnosed with a mental health disorder & 13 & 41.9 \\
\hline Previously received psychotherapy & 18 & 58.1 \\
\hline Previously received psychotropic medication & 14 & 45.2 \\
\hline
\end{tabular}

DSM-IV diagnostic criteria of generalised anxiety disorder (Spitzer et al., 2006). Item scores are summed with higher scores representing higher levels of anxiety $(\alpha=.71)$.

\section{Secondary Psychological Outcome Measures}

Penn State Worry Questionnaire

(PSWQ; Meyer, Miller, Metzger, \& Borkovec, 1990; translation by Gosselin, Dugas, Ladouceur, \& Freeston, 2001). The PSWQ is a 16-item trait measure of worry as found in generalised anxiety disorder. Item scores 
are summed with higher scores indicating higher levels of worry. The PSWQ is useful in distinguishing symptoms of generalised anxiety disorder from symptoms of other anxiety disorders. Adequate sensitivity (0.99) and specificity (0.98) have been reported (Behar, Alcaine, Zuellig, \& Borkovec, 2003; $\alpha=.93$ ).

\section{Liebowitz Social Anxiety Scale Self-Report}

(LSAS-SR; Liebowitz, 1987; French adaptation by Yao et al., 1999). The LSAS-SR is a 24-item rating scale that assesses fear and avoidance in social and performance-related situations. Item scores are summed with higher scores indicating higher levels of anxiety and avoidance $(\alpha=.96)$.

\section{Panic and Agoraphobia Scale}

(PAS; Bandelow, 1995; French-Canadian adaptation by Roberge, Marchand, Grenier, \& Marchand, 2003). The PAS is a 13-item measure of the severity of panic symptoms based on the diagnostic criteria of the DSM-IV for panic disorder with or without agoraphobia, with higher scores indicating more severe symptoms of panic disorder $(\alpha=.91)$.

\section{Satisfaction With Life Scale}

(SWLS; Diener, Emmons, Larsen, \& Griffin, 1985; translation by Blais, Vallerand, Pelletier, \& Brière, 1989). The SWLS is a 5-item measure of global life satisfaction. Item scores are summed with higher scores indicating higher satisfaction with life $(\alpha=.88)$.

\section{Translation}

The translation of the Wellbeing Course into the Cours Mieux-être was carried out by two bilingual members of the research team, including a clinical psychologist with expertise in the treatment of anxiety and depression using CBT. A professional translator reviewed the translation and translated the 'Do It Yourself guides and additional material. Differences of opinion were limited and focused primarily on maintaining a similar reading level. The translation was finalised after a consensus had been reached. The names in the vignettes were changed and statistics pertaining to Australia replaced by statistics relevant to Canada. During the posttreatment telephone interview, all study completers reported finding the program very easy to understand.

\section{Intervention}

The Wellbeing Course incorporates evidence-based components of cognitive behavioural therapy for anxiety and depression (Titov et al., 2013). It includes five lessons done over the course of eight weeks. Each lesson includes a 'Do It Yourself guide and additional resources (see Table 2 for additional information on the content of each lesson). No guidance from a clinician was provided to participants. However, as used by Titov and colleagues (2013), they did receive weekly, standardised emails that were translated for the purpose of this study. The emails provided directives, reminders, normalisation of challenges, and reinforcement of practice and progress.

\section{Procedure}

Memorandum of understanding

A memorandum of understanding was signed between Macquarie University and the Universite de Moncton to allow access to the Wellbeing Course and its translation for the purposes of this study.

Design

A single-group open trial, including a 3-month follow-up, was used. Outcome measures were administered at pretreatment, posttreatment, and at the 3-month follow-up. Treatment satisfaction was assessed at posttreatment only. 
Table 2. Wellbeing Course Lesson Content

\begin{tabular}{ll}
\hline Lesson & Lesson content \\
\hline Lesson 1 & $\begin{array}{r}\text { Education about the prevalence, symptoms and treatment of depression and anxiety including } \\
\text { information on how cognitive, behavioural and physical symptoms interact to produce poor } \\
\text { emotional health (Additional resources for Lesson 1: Step by Step guide, Problem Solving and Good } \\
\text { Sleep Guide). }\end{array}$ \\
\hline Lesson 2 & $\begin{array}{r}\text { Basic principles of cognitive therapy, including strategies for monitoring and challenging unhelpful } \\
\text { thoughs (Additional resources for Lesson 2: Managing Beliefs and Mental Skills). }\end{array}$ \\
\hline Lesson 3 & $\begin{array}{r}\text { Instructions on skills to manage physical symptoms including physical de-arousal strategies and } \\
\text { activity scheduling (Additional resources for Lesson 3: Worry Time, Communication Skills). }\end{array}$ \\
\hline Lesson 4 & $\begin{array}{r}\text { Education and guidelines on behavioural activation. Education and guidelines on avoidance and safety } \\
\text { behaviours and graded exposure (Additional resources for Lesson 4: Assertiveness Communication). }\end{array}$ \\
\hline Lesson 5 & Information on problem solving, relapse prevention and staying well. \\
\hline
\end{tabular}

\section{Safety}

Participants' levels of anxiety and depression were monitored at the beginning of each lesson using the GAD-7 and PHQ-9. If participants' scores increased by more than 5 points from the pretest and if their total score was $\geq 15$ on the PHQ-9, an email was sent that included information about mental health resources to use in case of an emergency. If participants' scores on the PHQ-9 were $\geq 20$ or if they answered ' 3 ' on question 9 (suicidal ideation), a management plan were to be provided. Over the course of the study, one participant was sent an email with emergency mental health resources, but his score decreased during the subsequent weeks of treatment. No participants scored $\geq 20$ on the PHQ-9 or answered ' 3 ' on question 9 (suicidal ideation) during the study.

\section{Results}

\section{Attrition and Adherence}

Four participants did not complete the posttreatment, two of whom formally withdrew during the treatment program due to time constraints and busy schedules. Posttreatment data were available for 25 participants $(80.6 \%)$ and follow-up data for 27 participants $(87.1 \%)$. As shown in Figure 1, the majority of participants completed all five lessons within the 8-week duration of the program $(n=23 ; 74.2 \%)$.

\section{Acceptability}

In response to the satisfaction questionnaire, $96 \%$ of the participants $(24 / 25)$ reported being mostly to totally satisfied with the program while one participant indicated being neither satisfied nor unsatisfied. None of the participants reported being unsatisfied. All participants (100\%) assessed the quality of the course as being good to excellent and reported that the course was worth doing and that they would recommend it to a friend with anxiety or depression. Answers to the open-ended questions revealed that nearly half of the participants reported that learning concrete psychological techniques, such as controlled breathing and thought challenging, was most helpful to them $(n=11 / 25 ; 44 \%)$, followed by reading the case-enhanced learning examples $(n=7 / 25,28 \%)$ and consulting the 'Do It Yourself guides $(n=3 / 25,12 \%)$. Several participants $(4 / 25,16 \%)$ reported that a few techniques, such as graded exposure, were less helpful to them, while others $(2 / 25,8 \%)$ found that not all case stories were relevant to them. This may have been as a result of having either anxiety or depression, the program addressing both problems. None of the participants mentioned the lack of clinical guidance as being a limitation of the program. 


\section{Preliminary Treatment Efficacy}

Changes in outcome measures from T1 (pretest) to T2 (posttest) and to T3 (3-month follow-up) were evaluated using intent-to-treat one-way repeated measures analysis of variance (ANOVAs) with the last observation carried forward model (LOCF).

\section{Primary psychological outcome measures}

A one-way repeated measures ANOVA examining changes on the PHQ-9 revealed a significant and large effect for time on both primary outcome measures: PHQ-9, $F(2,29)=30.36, p<.0001$, multivariate partial eta squared $=.68$; and GAD $-7, F(2,29)=38.43, p<.0001$, multivariate partial eta squared $=.73$. For the PHQ-9 as well as the GAD-7, pairwise comparisons using Bonferroni corrections for multiple comparisons revealed that the mean score for T1 was significantly different from $\mathrm{T} 2$ and T3. No significant difference was found between T2 and T3 (see Table 3 for means and standard deviations). Changes in means on the PHQ-9 and GAD-7 from T1 to T3 are displayed in Figure 2. Figure 3 shows changes in the proportion of participants from T1 to T2 and T3 at each level of severity of the PHQ-9 and the GAD-7. A decrease can be observed in the severity of symptoms after treatment, with the majority of participants scoring within the normal range of symptoms at T2 and T3.

\section{Secondary psychological outcome measures}

One-way repeated measures ANOVAs revealed significant and large effects for time on all secondary measures: PSWQ, $F(2,29)=9.60, p=.001$, multivariate partial eta squared $=.40$; LSAS-SR, $F(2,29)=$ $7.28, p=.003$, multivariate partial eta squared $=.33$; PAS, $F(2,29)=7.09, p=.003$, multivariate partial eta squared $=.33$; and SWLS, $F(2,29)=10.79, p<.0001$, multivariate partial eta squared $=.43$. Pairwise comparisons using Bonferroni corrections for multiple comparisons revealed that the mean score for $\mathrm{T} 1$ was significantly different from T2 and T3. There were no significant differences in scores between T2 and T3 (see Table 3 for means and standard deviations).

\section{Remission Rates and Deterioration}

At T1, 17 (55\%) participants had PHQ-9 scores at or above the clinical cut-off $(\geq 10)$, while $23(74 \%)$ had GAD-7 scores at or above the clinical cut-off $(\geq 8)$. Of these participants, $10 / 17$ (59\%) showed remission on the PHQ-9 at T2, and 17/23 (73.9\%) on the GAD-7. At T3, 14/17 (82.3\%) showed remission on the PHQ-9 and 16/23 (69.6\%) on the GAD-7. No participants showed a deterioration at T1 or T2, defined by an increase of at least 5 points on the PHQ-9 or GAD-7 compared to T1 scores (Titov et al., 2013).

\section{Discussion}

This study aimed to examine the feasibility of a French translation of the transdiagnostic iCBT program Wellbeing Course when delivered in a self-guided format for the treatment of anxiety and depression. Feasibility outcomes included treatment adherence, attrition, acceptability, and a preliminary assessment of the therapy's efficacy. The results obtained for each of these feasibility outcomes were satisfactory. All study hypotheses were supported. These preliminary findings are consistent with those obtained by Titov et al. (2013) using the original English version of the Wellbeing Course with a self-guided format and standardised emails. A slightly higher rate of treatment adherence was achieved in this study (67.7\%) compared to Titov et al. (58\%). Very few participants dropped out despite the use of a self-guided administration. Treatment satisfaction was high with nearly all participants reporting being mostly to totally satisfied and all of them reporting that the Wellbeing Course was worth their time and that they would recommend it to a friend. This high rate of satisfaction is similar to the clinician-guided version of the program (Titov et al., 2011). Similarly to Titov et al. (2013), significant and large improvements were found at posttreatment, and gains were maintained at follow-up with accompanying high levels of remission. There was no evidence of deterioration at posttreatment or 
Table 3. Means, Standard Deviations and Effect Sizes for Time (Partial Eta Squared; $\eta_{p}^{2}$ ) for All Psychological Outcome Measures $(n=31)$

\begin{tabular}{lllll}
\hline & T1 & T2 & T3 & \\
Variable & $M(S D)$ & $M(S D)$ & $M(S D)$ & $\eta_{p}^{2}$ \\
\hline PHQ-9 & $10.58(4.31)$ & $4.87(4.10)$ & $4.61(3.21)$ & 0.68 \\
\hline GAD-7 & $10.52(3.38)$ & $4.35(3.98)$ & $4.68(4.21)$ & 0.73 \\
\hline PSWQ & $55.61(11.55)$ & $49.68(11.16)$ & $46.74(12.11)$ & 0.40 \\
\hline LSAS-SR & $65.35(26.93)$ & $51.68(24.48)$ & $49.68(26.33)$ & 0.33 \\
\hline PAS & $12.97(9.70)$ & $8.39(8.47)$ & $7.52(7.86)$ & 0.33 \\
\hline SWLS & $21.39(6.35)$ & $24.55(6.61)$ & $23.84(6.56)$ & 0.43 \\
\hline
\end{tabular}

Note: T1 = pretest; T2 = posttest, T3 = follow-up; PHQ-9 = Patient Health Questionnaire-9; GAD-7 = Generalized Anxiety Disorder-7; PSWQ = Penn State Worry Questionnaire; LSAS-SR = Liebowitz Social Anxiety Scale Self-Report; PAS = Panic and Agoraphobia Scale; SWLS = Satisfaction with Life Scale.

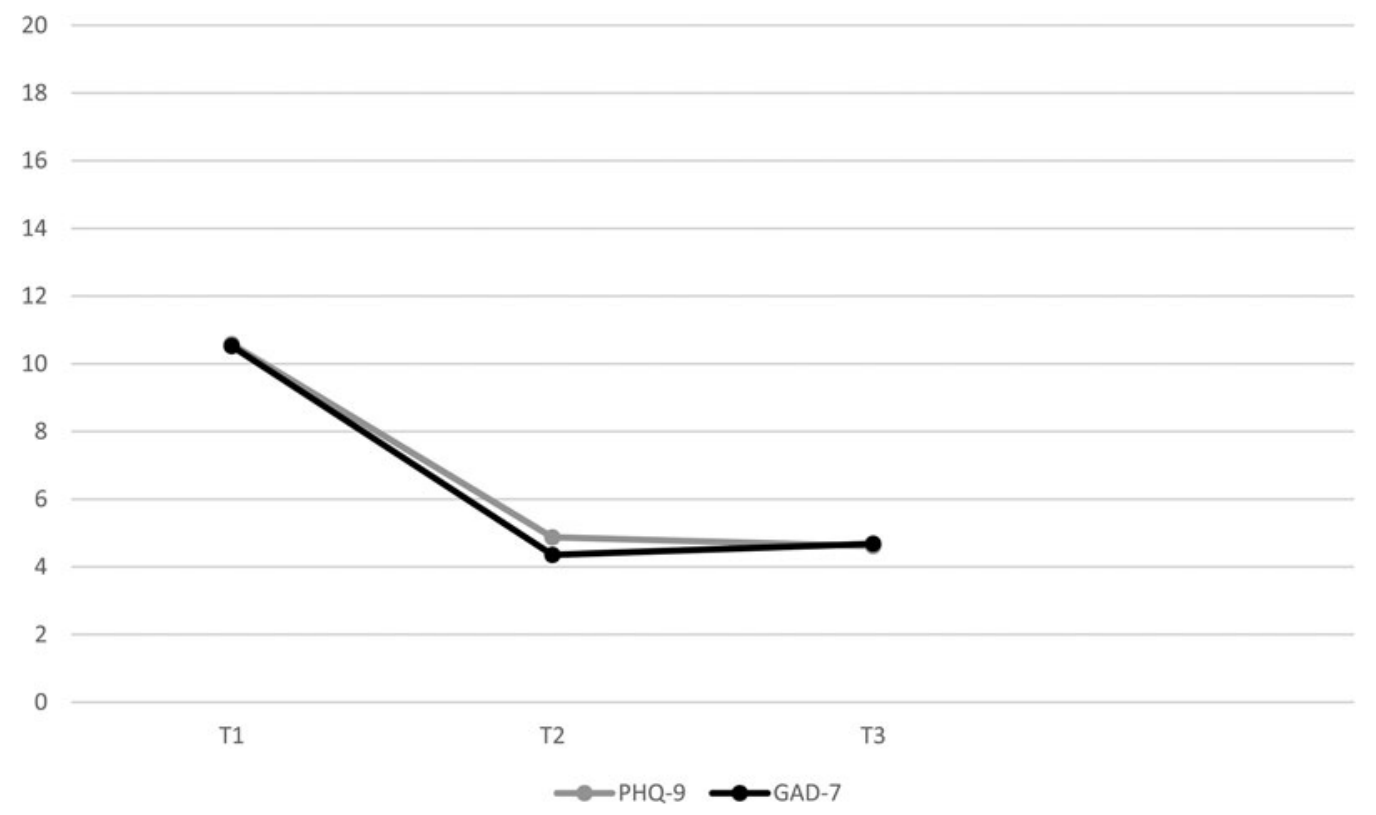

Figure 2. Means on the PHQ-9 and GAD-7 at T1, T2 and T3.

Note: T1 = pretest; T2 = posttest; T3 = follow-up; PHQ-9 = Patient Health Questionnaire-9 items; GAD-7 = Generalised Anxiety Disorder-7.

follow-up, suggesting that a self-guided format can be safely used. The current study also suggests that the program can have a significant impact on generic and disorder-specific measures of anxiety, which had not been assessed yet using the self-guided English version. This is adding further support to the value of transdiagnostic treatments when used with a self-guided delivery. Furthermore, the Wellbeing Course had a significant impact on life satisfaction, suggesting that improvements following the Wellbeing Course may generalise to broader domains of life.

These initial results using the self-guided version of the Wellbeing Course are similar to those obtained using the guided English version of the program in Australia (Dear et al., 2011; Titov et al., 2011) and Canada (Hadjistavropoulos et al., 2016). Clinician contact may not be essential when using this program (Titov et al., 2013). A series of randomised controlled trials have shown 

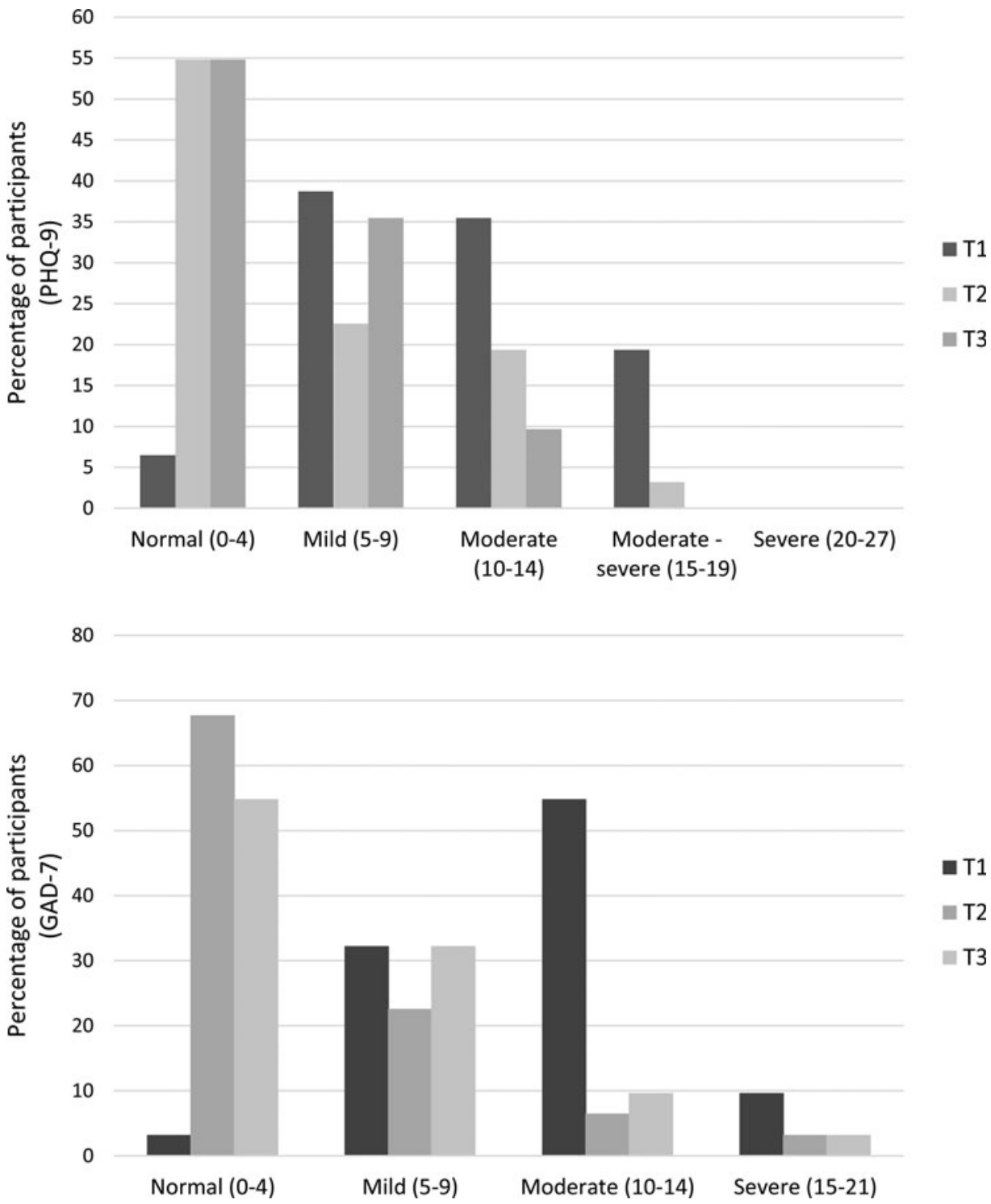

Figure 3. Change in PHQ-9 and GAD-7 scores from T1 to T2 and T3 based on severity among participants. Note: $\mathrm{T} 1$ = pretest; $\mathrm{T} 2$ = posttest; $\mathrm{T} 3$ = follow-up; PHQ-9 = Patient Health Questionnaire-9; GAD-7 = Generalised Anxiety Disorder-7.

that the self-guided Wellbeing Course produces similar clinical outcomes, treatment completion, and satisfaction rates to guided iCBT programs for social anxiety disorder, panic disorder, generalised anxiety disorder, and major depressive disorder (Dear et al., 2016; Dear et al., 2015; Fogliati et al., 2016; Titov, Dear, Staples, Terides et al., 2015).

Limitations of this study merit consideration. The first limitation is that this was a feasibility study that involved a small sample size study and no comparison or control group. Consequently, it is not possible to make any conclusions about the efficacy of treatment beyond that of spontaneous remission. However, it is important to note that the magnitude of change on the symptom measures observed was large and consistent with earlier trials of the Wellbeing Course, which were much larger 
and involved control groups (Titov et al., 2013; Titov et al., 2014; Titov et al., 2011). Our preliminary findings are superior to those of control groups involved in such pre-existing studies and support the initial effectiveness of the French-Canadian version of the program and generalisability of our findings. For example, control group remission rates obtained on the PHQ-9 and the GAD-7 using the clinician-guided English version of the Wellbeing Course were $24.1 \%$ and $21.9 \%$ respectively (Titov et al., 2013). Nonetheless, additional research involving control groups is needed, and the encouraging findings of the current study provide the necessary support for larger scale randomised controlled trials. A limit to generalisability of our results was that our participants were mainly women (75.9\%) and had high levels of education. Additional limitations of the study include the use of selfreport measures, rather than diagnostic interviews, in an attempt to simulate an automated and publicly available website. The follow-up was brief, but the findings from the original version of the selfguided Wellbeing Course suggest that treatment gains can be maintained for up to 12 months (Titov et al., 2014).

Based on the evaluation criteria for feasibility outcomes proposed by Thabane and colleagues (2010), this study suggests that future research on the translated self-guided version of the Wellbeing Course is feasible with no modifications required. Findings for each of the feasibility outcomes are encouraging and suggest that this version of the Wellbeing Course may reduce anxiety and depression among French-speaking people. The translation of transdiagnostic iCBT programs and their delivery in a self-guided format including strategies to ensure adherencse and retention may facilitate the cross-cultural dissemination of iCBT. This is of particular relevance in countries where there is a shortage of psychologists, limited access to iCBT and several linguistic communities.

Acknowledgments. This study was supported by a grant by the New Brunswick Health Research Foundation under Grant 2014-OPER-727. The French-Canadian translation of the Wellbeing Course was made possible in part with the financial assistance of the Translation Assistance Program of Alianco. We also thank Accra Solutions Inc. for their technical assistance throughout the study.

Declaration of Interest. None.

\section{References}

Andrews G, Cuijpers P, Craske M, McEvoy P and Titov N (2010) Computer therapy for the anxiety and depressive disorders is effective, acceptable and practical health care: A meta-analysis. PLoS ONE 5, e13196. doi:10.1371/ journal.pone.0013196

Bandelow BB (1995) Assessing the efficacy of treatments for panic disorder and agoraphobia: II. The Panic and Agoraphobia Scale. International Clinical Psychopharmacology 10, 73-81. doi:10.1097/00004850-199506000-00003

Behar E, Alcaine O, Zuellig AR and Borkovec TD (2003) Screening for generalized anxiety disorder using the Penn State Worry Questionnaire: A receiver operating characteristics analysis. Journal of Behavior Therapy and Experimental Psychiatry 34, 25-43. http://dx.doi.org/10.1016/S0005-7916(03)00004-1

Blais MR, Vallerand RJ, Pelletier LG and Brière NM (1989) L'Échelle de satisfaction de vie: Validation canadiennefrançaise du 'Satisfaction With Life Scale'. Canadian Journal of Behavioural Science 21, 210-223. doi:10.1037/h0079854

Choi I, Zou J, Titov N, Dear B, Li S, Johnston L ... Hunt C (2011) Culturally attuned internet treatment for depression amongst Chinese Australians: A randomized controlled trial. Journal of Affective Disorder 136, 459-468. doi:10.1016/ j.jad.2011.11.003

Dear BF, Staples LG, Terides MD, Fogliati VJ, Sheehan J, Johnston L and Titov N (2016) Transdiagnostic versus disorderspecific and clinician-guided versus self-guided internet-delivered treatment for social anxiety disorder and comorbid disorders: A randomized controlled trial. Journal of Anxiety Disorders 42, 30-44. http://dx.doi.org/10.1016/j.janxdis.2016.05. 004

Dear BF, Staples L, Terides MD, Karin E, Zou J, Johnston L, ... \& Titov N (2015) Transdiagnostic versus disorder-specific and clinician-guided versus self-guided internet-delivered treatment for generalized anxiety disorder and comorbid disorders: A randomized controlled trial. Journal of Anxiety Disorders 36, 63-77. http://dx.doi.org/10.1016/j.janxdis.2015.09.003

Dear BF, Titov N, Schwencke G, Andrews G, Johnston L, Craske MG and McEvoy P (2011) An open trial of a brief transdiagnostic internet treatment for anxiety and depression. Behaviour Research and Therapy 49, 830-837. doi:10.1016/ j.brat.2011.09.007

Diener E, Emmons RA, Larsen RJ and Griffin S (1985) The Satisfaction with Life Scale. Journal of Personality Assessment 49, 71-75. 
Fogliati VJ, Dear BF, Staples LG, Terides MD, Sheehan J, Johnston L and Titov N (2016) Disorder-specific versus transdiagnostic and clinician-guided versus self-guided internet-delivered treatment for panic-disorder and comorbid disorders: A randomized controlled trial. Journal of Anxiety Disorders 39, 88-102. http://dx.doi.org/10.1016/j.janxdis.2016.03.005

Gosselin P, Dugas MJ, Ladouceur R and Freeston MH (2001) Évaluation des inquiétudes: Validation d'une traduction française du Penn State Worry Questionnaire. Encephale 27, 475-84. doi:ENC-11-2001-27-5-0013-7006-101019-ART10

Hadjistavropoulos HD, Nugent MM, Alberts NM, Staples L, Dear BF and Titov N (2016) Transdiagnostic Internetdelivered cognitive behaviour therapy in Canada: An open trial comparing results of a specialized online clinic and nonspecialized community clinics. Journal of Anxiety Disorders 42, 19-29. http://dx.doi.org/10.1016/j.janxdis.2016.05.006

Hedman E, Andersson G, Lindefors N, Gustavsson P, Lekander M, Rück C and Ljótsson B (2014) Personality change following internet-based cognitive behavior therapy for severe health anxiety. PloS One 9, 1-18. doi:10.1371/ journal.pone.0113871

Hedman E, Ljótsson B, Kaldo V, Hesser H, El Alaoui S, Kraepelien M and Lindefors N (2013) Effectiveness of internetbased cognitive behavior therapy for depression in routine psychiatric care. Journal of Affective Disorders 155, 49-58. http://dx.doi.org/10.1016/j.jad.2013.10.023

Hedman E, Ljótsson B, Rück C, Bergström J, Andersson G, Kaldo, ... Lindefors N (2013) Effectiveness of Internet-based cognitive behaviour therapy for panic disorder in routine psychiatric care. Acta Psychiatrica Scandinavica 128, $457-467$. doi:10.1111/acps.12079

International Organisation of La Francophonie. (2018) Retrieved from https://www.francophonie.org/Welcome-to-theInternational.html

Kayrouz R, Dear BF, Johnston L, Gandy M, Fogliati VJ, Sheehan J and Titov N (2015) A feasibility open trial of guided Internet-delivered cognitive behavioural therapy for anxiety and depression among Arab Australians. Internet Interventions 2, 32-38. http://dx.doi.org/10.1016/j.invent.2014.12.001

Klein B, Meyer D, Austin D and Kyrios M (2011) Anxiety online - A virtual clinic: Preliminary outcomes following completion of five fully automated treatment programs for the anxiety disorders and symptoms. Journal of Medical Internet Research 13, e89.

Kroenke K, Spitzer RL and Williams JBW (2001) The PHQ-9: Validity of a brief depression severity measure. Journal of General Internal Medicine 16, 606-613.

Liebowitz MR (1987) Social phobia. In TA Ban, P Pichot, \& W Poldinger (Eds.), Modern problems of pharmacopsychiatry (pp. 141-173). New York, NY: Karger.

Lintvedt OK, Griffiths KM, Eisemann M and Waterloo K (2013) Evaluating the translation process of an Internet-based self-help intervention for prevention of depression: A cost-effectiveness analysis. Journal of Medical Internet Research 15, e18. doi:10.2196/jmir.2422

MAPI Research Institute. (2016) MAPI health research and commercialization. Retrieved from https://mapigroup.com/.

Mewton L, Smith J, Rossouw P and Andrews G (2014) Current perspectives on internet-delivered cognitive behavioural therapy for adults with anxiety and related disorders. Psychology Research and Behavior Management 7, 37-46. http:/ dx.doi.org/10.2147/PRBM.S40879

Mewton L, Wong N and Andrews G (2012) The effectiveness of internet cognitive behavioral therapy for generalized anxiety disorder in clinical practice. Depression and Anxiety 29, 843-849. doi10.1002/da.21995

Meyer TJ, Miller ML, Metzger RL and Borkovec TD (1990) Development and validation of the Penn state worry questionnaire. Behaviour Research and Therapy 28, 487-495. http://dx.doi.org/10.1016/0005-7967(90)90135-6

Olthuis JV, Watt MC, Bailey K, Hayden JA and Stewart SH (2016) Therapist-supported internet cognitive behavioural therapy for anxiety disorders in adults. Cochrane Database of Systematic Reviews, Issue 3. Art. No.: CD011565. doi:10.1002/14651858.CD011565.pub2.

Priemer M and Talbot F (2013) CBT guided self-help compares favorably to gold standard therapist-administered CBT and shows unique benefits over traditional treatment. Behaviour Change 30, 227-240. doi:10.1017/bec.2013.22

Ritterband LM, Andersson G, Christensen HM, Carlbring P and Cuijpers P (2006) Directions for the International Society for Research on Internet Interventions (ISRII). Journal of Medical Internet Research 8, e23. doi:10.2196/jmir.8.3.e23

Roberge P, Marchand L, Grenier S and Marchand A (2003) Validation Canadienne-Française de l'Échelle d'évaluation de la panique et de l'agoraphobie. Canadian Journal of Behavioural Science/Revue canadienne des sciences du comportement $\mathbf{3 5}$, 61-66. doi:10.1037/h0087188

Spitzer RL, Kroenke K, Williams JBW and Löwe B (2006) A brief measure for assessing generalized anxiety disorder: the GAD-7. Archives of Internal Medicine 166, 1092-1097. doi:10.1001/archinte.166.10.1092

Thabane L, Ma J, Chu R, Cheng J, Ismaila A, Rios LP and Goldsmith CH (2010) A tutorial on pilot studies: the what, why and how. BMC Medical Research Methodology 10, 1. doi:10.1186/1471-2288-10-1

Titov N, Dear BF, Johnston L, Lorian C, Zou J, Wootton B and Rapee RM (2013) Improving adherence and clinical outcomes in self-guided internet treatment for anxiety and depression: Randomised controlled trial. PLoS ONE 8, e62873. doi: 10.1371/journal.pone.0062873

Titov N, Dear BF, Johnston L, McEvoy PM and Wootton B, Terides MD and Rapee RM (2014) Improving adherence and clinical outcomes in self-guided internet treatment for anxiety and depression: A 12-month follow-up of a randomised controlled trial. PLOS ONE 9, e89591. doi:10.1371/journal.pone.0089591 
Titov N, Dear BF, Schwencke G, Andrews G, Johnston L, Craske MG and McEvoy P (2011) Transdiagnostic internet treatment of anxiety and depression: A randomised controlled trial. Behaviour Research and Therapy 49, 441-452. doi:10.1016/ j.brat.2011.03.007

Titov N, Dear BF, Staples LG, Bennett-Levy J, Klein B, Rapee RM and Nielssen O (2015) MindSpot Clinic: An Accessible, Efficient, and Effective Online Treatment Service for Anxiety and Depression. Psychiatric Services 66, 1043-1050. doi:10.1176/appi.ps.201400477

Titov N, Dear BH, Staples LG, Bennett-Levy J, Klein B, Rapee RM and Nielssen O (2016) The first 30 months of the Mindspot Clinic: Evaluation of a national e-mental health service against project objectives. Australian and New Zealand Journal of Psychiatry, 1-13. doi:10.1177/0004867416671598

Titov N, Dear BF, Staples L, Terides MD, Karin E, Sheehan J and McEvoy PM (2015) Disorder-specific versus transdiagnostic and clinician-guided versus self-guided treatment for major depressive disorder and comorbid anxiety disorders: A randomized controlled trial. Journal of Anxiety Disorders 35, 88-102. http://dx.doi.org/10.1016/j.janxdis.2015.08.002

Williams AD and Andrews G (2013) The effectiveness of internet cognitive behavioural therapy (iCBT) for depression in primary care: A quality assurance study. PLOS ONE 8, e57447. http://dx.doi.org/10.1371/journal.pone.0057447

Yao SN, Note I, Fanget F, Albuisson E, Bouvard M, Jalenques I and Cottraux J (1999) L'anxiété sociale chez les phobiques sociaux: Validation de l'Échelle d'anxiété sociale de Liebowitz (version française). L'Encéphale 25, 429-435.

Cite this article: DaPonte D, Talbot F, Titov N, Dear BF, Hadjistavropoulos HD, Hadjistavropoulos T, Jbilou J (2018). Facilitating the Dissemination of iCBT for the Treatment of Anxiety and Depression: A Feasibility Study. Behaviour Change 35, 139-151. https://doi.org/10.1017/bec.2018.14 